\title{
Youtube nas bibliotecas universitárias brasileiras: quem, como e para o que é utilizado
}

\begin{abstract}
Enrique Muriel-Torrado
\end{abstract}
Marcio Gonçalves

\begin{abstract}
Professor Doutor do Departamento de Ciências da Informação da UFSC. Professor do Programa de Pós Graduação em Ciências da Informação (PGCIN) da UFSC
\end{abstract}

Professor no Ibmec/RJ, Facha e Universidade Estácio de Sá

http://dx.doi.org/10.1590/1981-5344/2994

Apresenta o uso da mídia social YouTube como plataforma capaz de servir às atividades do profissional de ciência da informação e de biblioteconomia. Relaciona as práticas audiovisuais de bibliotecas que promovem ações e coloca em questão a importância do bibliotecário como produtor de conteúdo em ambiente digital. Os resultados da pesquisa servem como material referencial para profissionais de informação e gestores de unidades de informação que queiram investir no compartilhamento da informação em ambiente digital como forma de relacionamento com os públicos de interesse da organização em que atuam. Conclui-se que é importante planejar as ações de comunicação em plataformas de mídias sociais de forma a que o conteúdo seja relevante para os seguidores dos canais em audiovisual produzidos pelas bibliotecas universitárias brasileiras.

Palavras-chave: Bibliotecas universitárias; Serviços online; Mídia social; Inovação; Vídeos. 


\title{
Youtube in brazilian academic libraries: who, how and for what is
}

\begin{abstract}
This research aims to analyze the use of Youtube as a useful platform for the activities of library and information science professionals in brazilian academic libraries. Related audiovisual practices of the university libraries to encourage activities and focus on the importance of the librarian as a content producer in the digital enviroment. The survey results serve as reference material for information scientists and managers of information units interested in sharing audiovisual information as a new way of relationship with their users. Finally, based on the results, it is recommended to plan the communication strategy on social media platforms as YouTube, and prepare relevant content to engage with their subscribers and users.
\end{abstract}

Keywords: Academic libraries; Online Services; Social Media; Innovation; Videos.

Recebido em 06.11.2016 Aceito em 22.08.2017

\section{Introdução}

A oferta de serviços e de produtos por instituições, independente da área em que atuam, torna-se um diferencial competitivo diante da economia da atenção. O desafio pela inovação e pela (re)conquista de clientes e usuários passa a ser item constante da pauta de gestores. Nas organizações que trabalham na prestação de serviços de informação é mais urgente a necessidade de alcançar os públicos de interesse que, com a mobilidade e a popularização do acesso à internet de banda larga, estão acessando informação em diversas mídias e plataformas sociais de interação.

Nas unidades de informação, especificamente as bibliotecas, percebe-se grande esforço em criar novas ofertas de prestação de serviços mediados por tecnologia digital. Surge, assim, uma pergunta que merece resposta por parte dos atuais e futuros bibliotecários: as mídias sociais, aqui restrita ao YouTube, encorajam os profissionais de informação na produção de conteúdo que atenda as necessidades de interação dos usuários de internet?

Ao longo das seções desta pesquisa estão reflexões acerca da importância do compartilhamento de informação em ambiente digital de 
forma a entender se a produção, especificamente de conteúdo audiovisual para circular no canal do YouTube das bibliotecas das universidades brasileiras melhor posicionadas no ranking Webometrics, promove mais interação e engajamento dos usuários que navegam na web.

O estudo tem como objetivo analisar a prestação de serviços que transcendem o espaço físico destas bibliotecas e entender se encontram no ciberespaço uma oportunidade de construção de material em áudio e vídeo para circular nos espaços determinados a elas na mídia social YouTube. As conclusões servirão para guiar novas iniciativas por parte de bibliotecas que ainda não fazem uso de serviços online aos usuários. Os resultados da análise, que mostram os comparativos entre serviços e os conteúdos produzidos pelas bibliotecas, enriquecem o campo da biblioteconomia por ampliar a visão de atuação destes profissionais de informação. Os bibliotecários devem reconhecer no ambiente digital novas possibilidades de promoção de engajamento das unidades de informação com os usuários mediados pelas tecnologias de mídias sociais.

\section{Inovação e produção de cultura social no compartilhamento da informação}

A dinâmica das práticas de inovação em diversos setores da economia - privado, público e terceiro setor - passa por desafios diários na intenção de criar melhor relacionamento entre os públicos de interesse de uma organização. Conforme já apontado por Dib et al. (2016) é fundamental, entretanto, a compreensão do conceito de inovação em si, para que não se confunda com avanço tecnológico ou invenção. No Manual de Oslo, inovação é compreendida como "[...] implementação de um produto (bem ou serviço) novo ou significativamente melhorado, ou um processo, ou um novo método de marketing, ou um novo método organizacional nas práticas de negócios, na organização do local de trabalho ou nas relações externas" (ORGANIZAÇÃ̃O DE COOPERAÇÃO E DESENVOLVIMENTO ECONÔMICO, 2005, p. 55).

Os indivíduos, neste sentido, passam a buscar constantemente a informação como um diferencial competitivo no ambiente de atuação profissional. É possível, a partir de um cenário favorável de contato com tecnologia e de produção em redes colaborativas, conseguir transformar a informação em conhecimento aplicável na criação de novos planos, com bom planejamento e realizado com bons resultados de execução. 0 bibliotecário, especificamente, de acordo com Dib et al. (2016), destaca que, em busca pela reinvenção da profissão, faz com que os profissionais dessa área adotem novas práticas de trabalho diante das atuais exigências e demandas dos usuários.

Os profissionais de ciência da informação e de biblioteconomia têm a informação como eixo central na atuação da prática diária. Na demanda por inovação, as ideias que passam pelo compartilhamento da informação com os públicos podem garantir uma visibilidade dos serviços e produtos que uma biblioteca, por exemplo, oferece aos usuários da mesma. Uma ação bem desenvolvida pode render uma cultura social capaz de 
enriquecer ainda mais o papel do cientista da informação e do bibliotecário na atual sociedade que vem sendo construída na base da informação, do conhecimento e da inteligência.

O termo social aqui empregado, junto da cultura, é utilizado para simbolizar o poder de a mídia social mudar os relacionamentos entre as pessoas dentro e fora de uma organização. "Essa "social-idade" reflete mais do que hábitos individuais. Refere-se a organizações que trabalham diferentemente das formas tradicionais das organizações" (KANTER; FINE, 2011, p. 55). Trabalhar socialmente desafia pressuposições organizacionais profundamente arraigadas em relação à liderança, aos papéis e à estrutura. "Ela força organizações a pensar firmemente sobre o que é importante gerenciar e o que pode ser deixado sem controle. A cultura social ataca o cerne do que as organizações valorizam e o modo como elas operam" (KANTER; FINE, 2011, p. 55).

Organizações com cultura social são capazes de usar a mídia social para se envolverem em conversações de duas vias sobre o trabalho da organização com as pessoas dentro e fora dela. No caso da biblioteca é o que se espera atualmente: que haja menos paredes e mais redes nas tarefas diárias. Saber escutar e refletir é o que se espera quando se está conectado, mesmo que apenas virtualmente, com usuários que usam o espaço digital para ampliar a conversação. Como destacam Kanter e Fine (2011, p. 55), a cultura social é capaz de fazer com que se aprecie a informalidade e a individualidade, mas que, sobretudo, entenda-se que estes não são indicativos de falta de cuidado, de profissionalismo e de qualidade. Pelo contrário, pois, na verdade, os usuários dos serviços de biblioteca conseguem atendimento além das estruturas rigorosas de controle muitas vezes impostas por bibliotecas e unidades de informação.

A inovação faz coro com a cultura social e nesse compasso entra o compartilhamento de informações, pois é o que o virtual permite fazer, praticamente, a custo zero: as bibliotecas podem enxergar neste argumento formas de agir no espaço digital e extrapolar os balcões de atendimento. Quanto ao compartilhamento de informações é essencial para aumentar a produtividade e gerar benefícios significativos. Melhora a capacidade das organizações e contribui para a aprendizagem organizacional, além de aperfeiçoar a eficiência e reduzir significativamente o custo de muitos produtos e serviços. Coletivamente, os benefícios que decorrem da partilha de informações contribuem fortemente para a democratização de oportunidades (TOMÁEL, 2012, p. 13).

No contexto das organizações, o "compartilhamento de informação constitui-se na troca de informações entre os parceiros, que produzem o aumento da visibilidade da cadeia que abastece os processos nos quais estão inseridos" (TOMÁEL, 2012, p. 13). O compartilhamento de informações pode ser visto como um sinal da vontade de uma organização para construir um relacionamento de longo prazo que ajuda no fortalecimento da parceria (TOMÁEL, 2012, p. 13-14). A informação, neste caso, é um processo de formação de sentido dos fatos - resultante do saber, dos acontecimentos, das especulações, das ações e dos projetos - 
cujo conteúdo é permutado com o ambiente em que se está inserido. A "informação pode confirmar fatos e tendências, gera a acumulação do conhecimento, construindo memória. Propaga-se no tempo e no espaço, e, para se tornar pública, utiliza os meios de comunicação" (TOMÁEL, 2012, p. 15).

Como hoje pode-se dizer que há uma convivência das mídias, tanto das de massa quanto das sociais, a informação, que necessita de suporte para ser veiculada e assimilada pelos públicos, encontra, por exemplo, nos suportes das mídias audiovisuais uma chance de compartilhar informação e gerar maior engajamento dos usuários com os produtos e serviços de uma biblioteca e/ou unidade de informação.

\section{Ferramentas da web 2.0 nas bibliotecas universitárias}

Existem diversos estudos e análises sobre os tipos de ferramentas 2.0 usadas na biblioteca universitária em diferentes lugares do mundo (BRITO; SILVA, 2011; RIBEIRO; LEITE; LOPES, 2014; VIEIRA; BAPTISTA; CERVERÓ, 2013; TRIPATHI; KUMAR, 2010; SI; SHI; CHEN, 2011). Eles mostram como as bibliotecas são influenciadas pelos avanços tecnológicos que tão rapidamente chegam ao público geral na atual sociedade.

Para Holmberg et al. (2009) a Biblioteca 2.0 está baseada em 7 pilares: interatividade, usuários, participação, bibliotecas e serviços bibliotecários, web e web 2.0, aspectos sociais e, por último, tecnologia e as devidas ferramentas. Maness (2006) define 4 elementos fundamentais: centrada no usuário, oferece uma experiência multimídia, socialmente rico e inovadora para sua comunidade. O autor sugere que se tenha foco na importância de oferecer conteúdo de áudio e vídeo, resenhando, assim, o aspecto inovador: adaptar permanentemente seus serviços para encontrar novas formas de que sua comunidade compartilhe informação. Em ambas definições percebe-se a importância do usuário no centro de serviços e das atividades que, com a biblioteca 2.0, começa a ser, também, partícipe do que acontece na biblioteca, aumentando, consequentemente, 0 protagonismo do mesmo.

A biblioteca, antes "ilha" de informações visitada fisicamente por usuários que buscavam um produto, principalmente, o livro, precisa, agora, integrar-se e disputar espaço em um "mar de informações". Os usuários tornam-se progressivamente remotos e descorporificados, acostumam-se àquilo que se pode obter "aqui" e "agora": a informação digital instantânea disponibilizada pelas redes, em especial pela Internet, e pela crescente largura de banda disponível (LEVACOV, 2006, p. 210).

É justamente neste ponto que merece a reflexão de que o bibliotecário e o cientista da informação, como agentes de informação, entendam que a atuação dos serviços prestados possa atender a uma necessidade de tornar a biblioteca mais híbrida. Levacov (2006, p. 207) entende que a biblioteca híbrida é aquela que contém não apenas material impresso e magnético, mas também informação digital (em múltiplos formatos: mídias óticas on e off-line, como $C D-R O M s$ e DVDs, terminais 
para acesso a catálogos, banco de dados e a alguns dos variados tipos de documentos digitais).

Levacov (2006, p. 219), portanto, alerta que se o usuário não encontra o que procura em determinado lugar, o mesmo volta-se para outras opções oferecidas pela rede. No caso da biblioteca, considerando o espaço territorial que ocupa, encontrar-se "amarrada e amordaçada por conceitos tradicionais e obsoletos" fará com que outras fontes de informação equivalentes surjam rapidamente". É o caso de aproveitar o virtual e o espaço digital para produzir o que Maness alertara anteriormente: produzir áudio e vídeo. Assim, a pesquisa mostra como a mídia social YouTube tem sido usada por determinadas bibliotecas de forma a atender a demanda de certos usuários mais engajados digitalmente.

A "segunda tela" é aquela que o telespectador utiliza ao mesmo tempo que olha para sua tela de televisão: pode ser um smartphone, um tablet ou um laptop, por exemplo (MARTEL, 2015, p. 340). Para entender a internet e a cultura que estão por vir, é importante observar as novas ferramentas decisivas que surgiram nos últimos anos: as redes sociais, que oferecem novas formas de conversa; os aplicativos, um fenômeno importante que vem tomar o lugar dos sites no smartphone; o "curtir" do Facebook, que serve para a recomendação, como também os "retuítes" do Twitter; a hashtag, o dashboard, os feeds de notícias e as linhas do tempo das redes sociais, que permitem se localizar; a Social TV, que permite a proliferação dos diálogos etc. (MARTEL, 2015, p. 446).

YouTube é a maior plataforma de distribuição de vídeo na atualidade. No Brasil é o segundo site mais acessado do mundo ${ }^{1}$, só depois do Google, que é o dono da mesma. A companhia, que oferta 76 idiomas diferentes e apresenta versões locais em 88 países, calcula ter um de cada três usuários da internet assistindo aos seus vídeos. O sucesso entre o público jovem e sua aposta pelos dispositivos móveis conseguem que os dispositivos portáteis atraiam mais da metade das visualizações totais (YOUTUBE, [2016?]).

O YouTube não se enquadra mais na definição pura de sistema emergente. Embora comparado com a TV, ainda não é considerado hegemônico como meio de comunicação de massa. Mas o maior portal de compartilhamento de vídeos da web tem o DNA digital, cresceu e se mantém conforme as regras do ambiente comunicacional emergente (RIBEIRO, 2013, p. 14). Entre os grandes portais de vídeo, o YouTube é o que oferece as maiores possibilidades de ser utilizado como uma mídia social: a publicação e exibição dos vídeos são gratuitas (RIBEIRO, 2013, p. 103). Assim como a TV, despertou o interesse da publicidade como espaço de mídia e cobra para que marcas anunciem em diversos formatos ao longo da apresentação dos vídeos. O alcance do portal, as facilidades para a manutenção de um canal e o acesso gratuito às ferramentas de

${ }^{1}$ ALEXA. Top sites in Brazil. Disponível em: <http://www.alexa.com/topsites/countries/BR>. Acesso em: 31 out. 2017. 
publicação e exibição de vídeos tornam o YouTube uma opção barata e atrativa (RIBEIRO, 2013, p. 103).

"O potencial de utilização de vídeos no lugar de textos acadêmicos e pesados, para atrair o público jovem a temas científicos, fez com que o YouTube passasse a ser utilizado como "um novo canal de ciências" por grupos de cientistas norte-americanos e europeus" (RIBEIRO, 2013, p. 104). "A emergência das redes e mídias sociais está construindo uma nova esfera pública para a disseminação do conhecimento a respeito de uma organização" (RIBEIRO, 2013, p. 144).

\section{Metodologia}

A pesquisa é de cunho exploratório e tem como finalidade "proporcionar maior familiaridade com o problema, com vistas a torná-lo mais explícito ou construir hipóteses" (GIL, 2010. p.27). Quanto aos meios de investigação pode ser classificada como documental, que é um tipo de pesquisa semelhante à pesquisa bibliográfica, mas diferenciada pelas fontes, "materiais que não recebem ainda um tratamento analítico" (GIL, 2002 p.45). A abordagem do assunto é eminentemente quantitativa: um método aplicado nos estudos descritivos, já que se procura descobrir as características de um fenômeno, isto é, averiguar "o que é" (RICHARDSON, 1989). Ver-se-á, entretanto, alguns aspectos qualitativos na seção das categorias.

Para conhecer as universidades melhor valoradas do Brasil utiliza-se o Ranking Web (Webometrics) de Universidades na sua edição do primeiro semestre de 2016. A classificação, que apresenta mais de 21.000 universidades, é um projeto do Cybermetrics Lab, um grupo de pesquisa do Consejo Superior de Investigaciones Científicas (CSIC) de Espanha. Webometrics tem por objetivo promover a publicação acadêmica por meio de apoio às iniciativas de acesso aberto, para incrementar a transferência de conhecimento das universidades a toda a sociedade (WEBOMETRICS, [2006?]). O ranking prioriza nas suas avaliações a presença das universidades na internet. Este é o motivo de escolha deste estudo porque o objetivo deste trabalho é identificar como o YouTube é usado nas principais bibliotecas das universidades mais reconhecidas do Brasil.

As 50 universidades brasileiras que aparecem melhor valoradas na edição de janeiro de 2016 do Webometrics são (em ordem): Universidade de São Paulo (USP), Universidade Estadual de Campinas (UNICAMP), Universidade Federal do Rio de Janeiro (UFRJ), Universidade Federal do Rio Grande do Sul (UFRGS), Universidade Federal de Santa Catarina (UFSC), Universidade Federal de Minas Gerais (UFMG), Universidade de Brasília (UnB), Universidade Federal do Paraná (UFPR), Universidade Federal Fluminense (UFF), Universidade Federal de São Paulo (UNIFESP), Universidade Federal do Ceará (UFC), Universidade Federal da Bahia (UFBA), Universidade Federal de Pernambuco (UFPE), Pontifícia Universidade Católica do Rio de Janeiro (PUC-Rio), Universidade do Estado do Rio de Janeiro (UERJ), Universidade Federal do Rio Grande do Norte (UFRN), Universidade Federal de São Carlos (UFSCar), Universidade 
Federal de Goiás (UFG), Universidade Estadual Paulista Júlio de Mesquita Filho (UNESP), Universidade Federal do Pará (UFPA), Pontifícia Universidade Católica do Rio Grande do Sul (PUCRS), Universidade Federal de Santa Maria (UFSM), Universidade Federal da Paraíba (UFPB), Universidade Estadual de Londrina (UEL), Universidade Federal de Viçosa (UFV), Universidade Estadual de Maringá (UEM), Universidade Federal do Amazonas (UFAM), Universidade Federal de Uberlândia (UFU), Universidade Federal de Pelotas (UFPEL), Universidade Federal de Juiz de Fora (UFJF), Pontifícia Universidade Católica do Paraná (PUCPR), Universidade Federal do Espírito Santo (UFES), Universidade Estadual de Montes Claros (UNIMONTES), Fundação Getúlio Vargas (FGV), Universidade Federal de Lavras (UFLA), Universidade Federal de Ouro Preto (UFOP), Universidade Federal do ABC (UFABC), Universidade Tecnológica Federal do Paraná (UTFPR), Universidade Federal de Campina Grande (UFCG), Universidade Federal de Mato Grosso do Sul (UFMS), Universidade do Vale do Rio dos Sinos (UNISINOS), Universidade Estadual de Feira de Santana (UEFS), Universidade Federal de São João del Rei (UFSJ), Universidade do Estado de Santa Catarina (UDESC), Universidade Federal do Rio Grande (FURG), Universidade de Santa Cruz do Sul (UNISC), Universidade Federal de Mato Grosso (UFMT), Universidade Federal de Itajubá (UNIFEI), Pontifícia Universidade Católica do Minas Gerais (PUC-MINAS) e Universidade Federal de Sergipe (UFS).

Uma vez identificadas as universidades, procurou-se os sites das bibliotecas centrais ou matriz de forma a saber se tinham um link no site da biblioteca direcionando para o canal no YouTube. Em seguida, foram analisados nome do usuário e data de criação do perfil, subscrições ao canal, listas de reprodução, url, imagem (foto e capa personalizada), vídeos inseridos na plataforma, categoria dos vídeos, datas, visualizações e duração dos mesmos. Os dados foram coletados através do YouTube entre 20 de agosto de 2016 e 10 de setembro do mesmo ano.

Para cada vídeo se assinou uma categoria baseada na observação seguida de uma breve análise do conteúdo: Ações, Entrevistas, Eventos, Formação, Institucional, Outros, Projetos e Rádio.

\section{Resultados: apresentação e discussão}

Das 50 bibliotecas universitárias analisadas apenas 20\% (10) apresentam um link ao canal do YouTube desde o site da biblioteca. É uma cifra baixa se pensar que é um canal de comunicação que permite compartilhamento de materiais de interesse para os usuários. Entre as 10 universidades brasileiras melhor posicionadas no Webometrics, é preciso descer até a quinta posição para se encontrar a primeira biblioteca com um canal de vídeo. Apenas 30\% das bibliotecas das universidades no top 10 apresentam um link ao perfil do YouTube.

$\mathrm{Na}$ Tabela 1 encontram-se as universidades da amostra com a posição em que ocupam no ranking brasileiro, no mundial, e os nomes da universidade e da biblioteca como aparecem no perfil do YouTube. Entre as universidades com presença na plataforma de vídeos, o financiamento 
público predomina - 9 das 10 da amostra são federais ou estaduais - a PUC-RIO aparece como a única privada. No relacionado com o ano de criação do perfil apenas 3 das bibliotecas disponibilizavam a informação: a biblioteca da UFSC, de 2010, e as da UNB e da UEL, as duas de 2011.

Tabela 1 - Universidades com bibliotecas centrais que têm perfil no YouTube

\begin{tabular}{c|c|l|l}
\hline $\begin{array}{c}\text { Ranking } \\
\text { Brasil }\end{array}$ & $\begin{array}{c}\text { Ranking } \\
\text { Mundial }\end{array}$ & \multicolumn{1}{|c}{ Universidade } & \multicolumn{1}{|c}{ Usuário } \\
\hline \hline 5 & 382 & $\begin{array}{l}\text { Universidade Federal de Santa Catarina } \\
\text { UFSC }\end{array}$ & BIBLIOTECASUFSC \\
\hline 6 & 398 & $\begin{array}{l}\text { Universidade Federal de Minas Gerais } \\
\text { UFMG }\end{array}$ & Biblioteca Universitária UFMG \\
\hline 7 & 426 & Universidade de Brasília UNB & BCE UnB \\
\hline 14 & 710 & $\begin{array}{l}\text { Pontifícia Universidade Católica do Rio de } \\
\text { Janeiro PUC-RIO }\end{array}$ & Bibliotecas PUC-Rio \\
\hline 23 & 1011 & Universidade Federal da Paraíba UFPB & Biblioteca Central UFPB \\
\hline 24 & 1069 & Universidade Estadual de Londrina & Bibliotecas UEL \\
\hline 30 & 1124 & Universidade Federal de Uberlândia & Bibliotecas UFU \\
\hline 42 & 1315 & Universidade Federal de Juiz de Fora UFJF & $\begin{array}{l}\text { Bibliotecas Universidade Federal } \\
\text { de Juiz de Fora }\end{array}$ \\
\hline 45 & 1636 & $\begin{array}{l}\text { Universidade Estadual de Feira de Santana } \\
\text { UEFS }\end{array}$ & SISBI UEFS - Biblioteca Viva \\
\hline
\end{tabular}

Fonte: Dados da pesquisa.

A Biblioteca da UFSC - com 311 inscritos - é sem dúvida a que tem mais assinantes do canal. Distante dela estão as bibliotecas da UEL, com menos da metade, 147, e da UFMG com apenas 51 assinantes. É preocupante que $40 \%$ dos canais da amostra tem menos de 10 assinantes. Pode-se inferir que é devido ao planejamento deficiente dos gestores uma vez que há uma estratégia de poucos conteúdos, pois, ou não são do interesse dos usuários ou talvez por falta mesmo de marketing e de publicidade na divulgação das ações.

Por outro lado, o uso de listas de reprodução é subestimado. Apenas $60 \%$ das bibliotecas as empregam e nem todas parecem seguir um critério. A Biblioteca da UFSC tem 3 listas: Vídeos sobre a BU (44); Vídeos favoritos (44); e SpringerLink: tutoriais (6). O canal da Biblioteca da PUCRio apresenta 6: Divulgação DBD - BiblioDivulga (6); Trailer filmes Rio450 (6); Filmes - Rio 2015: 450 páginas de história (12); Rio 2015: 450 páginas de história (31); Favoritos (2); Vídeos favoritos (2). Várias das listas pertencem a Rio450anos - um projeto para comemorar o aniversário da cidade do Rio de Janeiro.

A Biblioteca da UEL tem várias listas com apenas um vídeo: Bibliotecas da UEL lançam ficha catalográfica online; CHAT atendimento online; Restauração de livros na biblioteca da UEL; Biblioteca Digital da UEL; Biblioteca Setorial de Ciências Humanas completa 10 anos; Mau uso dos livros na biblioteca da UEL; Serviços por email; Semana Nacional do Livro e da Biblioteca 2014; Vídeo Sistema de Bibliotecas da UEL; Coleções de livros raros estão disponíveis no acervo do CDPH; Favoritos; UEL 
participa da $12^{a}$ Olimpíada Solidária de Estudo. E uma última lista, Vídeos favoritos, com 4.

A Biblioteca da UFU tem duas listas: Inserção de ficha catalográfica em trabalhos acadêmicos - Tutorial SISBI/UFU - vídeo 1 (1) e Sistema de Bibliotecas - SISBI/UFU (14). O canal do SISBI UEFS - Biblioteca Viva, não apresenta vídeos subidos no seu canal, simplesmente uma lista de reprodução com 10 vídeos, todos eles do perfil "TV Olhos D'Água", veículo de comunicação da Universidade Estadual de Feira de Santana. Por último, o SiBFURG, da FURG tem duas listas: Vídeos Favoritos e Favoritos, com 6 vídeos cada uma.

Como pode-se apreciar, o uso das listas de reprodução é diferente nas 6 bibliotecas, misturando critérios, como acontece em uma universidade que tem tanto Favoritos quanto Vídeos Favoritos, uma duplicidade que não parece necessária. A produção de vídeos por parte das bibliotecas é variada, tanto em quantidade, como nos objetivos que sustentam a realização dos mesmos. A Biblioteca da UFMG apresenta 0 maior número (92), mas, como acontece no caso da biblioteca da UNB (44), em sua maioria correspondem com vídeos de um mesmo evento ou categoria. A biblioteca da UFSC é, junto com a mencionada UNB, a segunda em total de vídeos (44). As cifras descem para as da PUC-Rio e FURG, que mostram números próximos: 22 e 23 vídeos cada uma. A parte baixa não chega a 5 vídeos (bibliotecas de UFJF, UEL, UFPB, UFU). Como se comentou anteriormente a biblioteca da UEFS não apresenta nenhum vídeo no canal: só uma lista de reprodução.

Uma vez que se conhece a quantidade de vídeos disponíveis nos perfis das bibliotecas é importante analisar o conteúdo dos mesmos a partir de oito categorias diferentes:

1- Ações: reúne as diferentes atividades empreendidas pela biblioteca, como o dia do bibliotecário, o dia da mulher, etc.;

2- Entrevistas: são pequenas peças onde aparecem os bibliotecários falando dos serviços das bibliotecas na TV ou feitas pela biblioteca a profissionais de reconhecido prestígio, como um professor;

3- Eventos: seminários, congressos, ou outros tipos de encontros;

4- Formação: são vídeos com tutoriais, dicas aos usuários para a utilização de um sistema, para conhecer melhor as regras $A B N T$, acessar a sua conta da biblioteca, etc.;

5- Institucional: onde se apresentam algumas características da biblioteca, oferta, instalações, serviços, etc.;

6- Outros: recolhe os vídeos que não entram dentro das outras categorias, como homenagens a companheiros bibliotecários; 
7- Projetos: são intervenções institucionais realizadas sob um projeto da biblioteca, que não é parte da atividade habitual;

8- Rádio: categoria ad hoc empregada apenas por uma universidade, que disponibiliza um programa de rádio.

Neste ponto é preciso resenhar o caso da biblioteca da UFMG, onde 89 de 92 (97\%) dos vídeos pertencem ao programa de rádio "No Ritmo da Lombada" que é feito em parceria entre o Sistema de Bibliotecas e a Rádio da UFMG. A categoria Rádio corresponde com 38\% do total dos vídeos da amostra. É preciso dizer que são áudios e não vídeos, pelo que seria mais recomendável se os apresentassem em outra plataforma otimizada para esse formato, que permitisse, por exemplo, baixar os podcasts ${ }^{2}$. Na Biblioteca da UNB acontece um caso parecido: todos os vídeos (44) correspondem com um único evento - a exposição 50 anos da BCE do ano 2012, pois o único aporte no YouTube é o evento.

Ações aparece nos canais das bibliotecas apenas $4 \%$, por enquanto, Entrevistas apenas alcança $1 \%$. As duas categorias têm um potencial que poderia ser aproveitado pelas bibliotecas, mas são poucas as que fazem uso. Eventos, além dos comentados vídeos da UNB, é usado pela biblioteca da UFSC, aproveitando para mostrar vídeos de algumas conferências ou eventos que aconteceram na biblioteca. Uma boa forma de deixar o registro do conhecimento comunicado por especialistas de diferentes áreas e compartilhar com todos os usuários.

Esta mesma biblioteca produz vídeos principalmente na Formação, sendo $48 \%$ da sua produção total. Antes de começar o presente artigo se pensou que a categoria mais destacada seria, sem dúvida, Formação, mas os dados são claros. Por um lado, a categoria corresponde apenas a $22 \%$ do total, por outro, das 9 bibliotecas com vídeos da amostra, 1 não tem nenhum e até 7 apresentam menos de 5 vídeos. Uma categoria na qual se poderiam oferecer tutoriais de acesso ao sistema da biblioteca, mostrar como utilizar os serviços, dicas sobre como pesquisar ou fazer citações, e uma infinidade de informações que podem ajudar aos seus usuários a utilizar os sistemas tanto da biblioteca, quanto da própria universidade, não parece estar muito explorada.

Institucional, que pode ser utilizado como ferramenta de marketing para apresentar o que a biblioteca pode fazer pelos seus usuários aparece apenas em 3 das 9 bibliotecas. Outros, com $1 \%$ é para homenagens a companheiros e um breve vídeo com música ao vivo para a abertura de um evento. Projetos aparece em $5 \%$ dos vídeos, entre eles está o Projeto Rio 450 anos da PUCRIO, ou Natal Solidário da biblioteca e a Arboreteca, os dois da biblioteca da FURG. Rádio, como se comentou, pertence exclusivamente à biblioteca da UFMG (89).

Tabela 2 - Categorias que apresentam os vídeos

\begin{tabular}{l|c|c|c|c|c|c|c|c}
\hline & Ações & Entrevistas & Eventos & Formação & Institucional & Outros & Projetos & Rádio \\
\hline \hline UFSC & 2 & 2 & 14 & 21 & 3 & 1 & 1 & 0 \\
\hline
\end{tabular}

${ }^{2}$ Podcasts são arquivos em áudio e que podem ser armazenados gratuitamente, por exemplo, no SoundCloud. 


\begin{tabular}{l|c|c|c|c|c|c|c|c}
\hline UFMG & 0 & 1 & 0 & 2 & 0 & 0 & 0 & 89 \\
\hline UNB & 0 & 0 & 44 & 0 & 0 & 0 & 0 & 0 \\
\hline PUCRIO & 3 & 0 & 0 & 8 & 5 & 0 & 6 & 0 \\
\hline UFPB & 0 & 0 & 0 & 2 & 0 & 0 & 0 & 0 \\
\hline UEL & 0 & 0 & 0 & 3 & 0 & 0 & 0 & 0 \\
\hline UFU & 0 & 0 & 0 & 1 & 0 & 0 & 0 & 0 \\
\hline UFJF & 0 & 0 & 0 & 4 & 0 & 0 & 0 & 0 \\
\hline UEFS & 0 & 0 & 0 & 0 & 0 & 0 & 0 & 0 \\
\hline FURG & 5 & 0 & 0 & 11 & 1 & 2 & 4 & 0 \\
\hline TOTAL & 10 & 3 & 58 & 52 & 9 & 3 & 11 & 89 \\
\hline
\end{tabular}

Fonte: Dados da pesquisa.

A plataforma YouTube oferece pouca informação sobre a data dos vídeos, mostrando simplesmente: "X anos atrás" ou "1 mês atrás". Foram recopiladas as datas anteriores a um ano, e depois se agruparam todos os postados há menos de um ano $(<1)$. Os vídeos mais antigos têm 6 anos $(1 \%)$, com 5 anos, $8 \%$, mesma percentagem para os que têm 4 anos. As cifras sobem para vídeos com 3 anos (24\%), com 2 (13\%) e com um ano $26 \%$. Aqueles com menos de um ano de antiguidade alcançam $21 \%$. A atualidade dos 235 vídeos analisados é razoável - 60\% dos vídeos têm como máximo dois anos de antiguidade - pelo que se poderia afirmar que são bastante atuais. $47 \%$ deles são produções vídeos de um ano ou menos. A biblioteca da UNB é a única que não subiu vídeos nos últimos anos. Como se viu todos os vídeos correspondem a 2012.

\section{Gráfico 1 - Antiguidade dos vídeos}

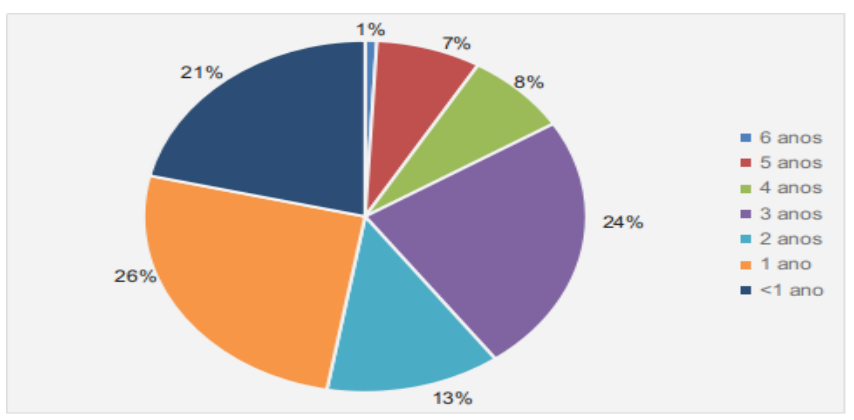

Fonte: Dados da pesquisa.

O vídeo com mais visualizações (42191) corresponde a "Como Fazer o Login", da biblioteca da UEL. Bem distante aparece a "Videoaula I: Portal Capes: visão geral", da Biblioteca da UFSC (7312), o "Minicurso de Currículo Lattes" da FURG (5558) e "Pesquisa Básica no Catálogo Online" da UFMG (4533). A biblioteca da PUCRIO supera as 1000 visualizações. Por enquanto as da UNB, UFPB, UFU e UFJF estão distante dessa cifra. Pode-se apreciar que os vídeos pertencem à categoria Formação: fazer login no sistema, acesso ao portal Capes e ao Lattes ou a pesquisa no catálogo são algumas das competências básicas que os usuários precisam 
ter e, provavelmente, alguns deles sejam de visualização obrigatória por parte dos usuários.

O gráfico 2 apresenta o vídeo mais visto junto ao total de visualizações por canal. É fácil comprovar como as visualizações da biblioteca da UEL dependem de um único vídeo. Em contrapartida a biblioteca da UFSC, que supera as 50.000 visualizações no canal, apenas $14 \%$ pertencem ao vídeo mais visto. Nos casos das bibliotecas da FURG e da UFMG apresentam uma maior dependência do vídeo mais visualizado, já que corresponde com $43 \%$ e $37 \%$ do total de visitas. Na UFJF e UFPB as cifras aumentam até $51 \%$ e $58 \%$. O canal da biblioteca da UNB é o que menor tem dependência do vídeo mais visualizado. Das 4066 ocasiões em que os vídeos foram assistidos, apenas $5 \%$ corresponde ao vídeo mais visto.

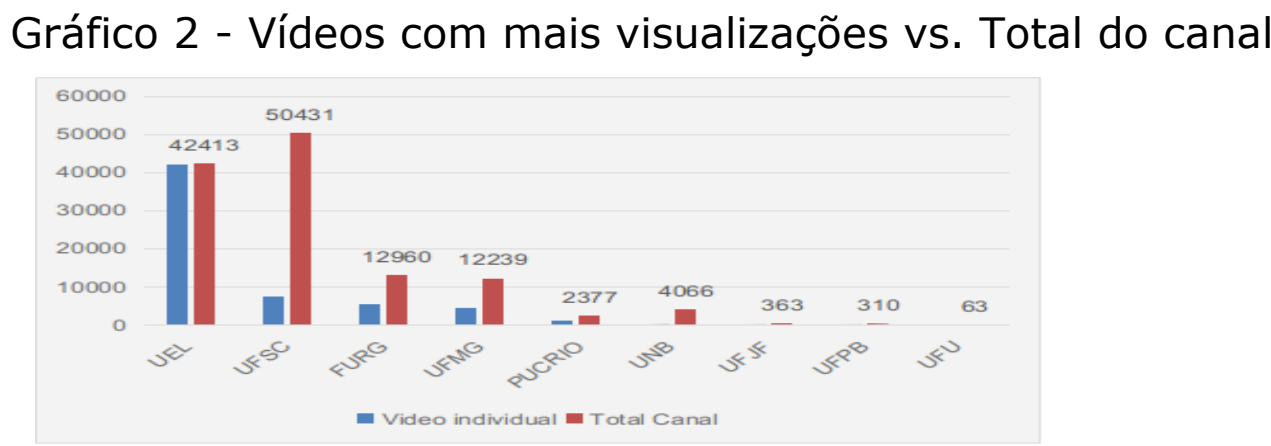

Fonte: Dados da pesquisa.

Em destaque está o vídeo da UFMG que consiste em uma entrevista ao prestigioso historiador Peter Burke, da Universidade de Cambridge (1242 visitas). Um bom exemplo de uma boa prática que as bibliotecas podem realizar no YotuTube. Como se aprecia no gráfico anterior alguns vídeos tiveram muitas visualizações, mas um número grande de vídeos foi visualizado em poucas ocasiões. Por este motivo o cálculo da média apresenta um forte desvio e não é representativo. Para tentar solucioná-lo é preciso um valor que ajude a contextualizar as visualizações dos canais, a mediana, que proporciona o valor típico quando um grupo de dados está desviado, como acontece neste caso. Assim, a mediana mais alta corresponde à biblioteca da UFSC (238), com muita distância da segunda, UEL (48), seguida das bibliotecas da FURG e da UNB (36). PUCRIO, UFMG, UFPB e UFU (12) estão na parte baixa, junto com a biblioteca da UFJF (8). Neste caso vê-se uma forte diferença da mediana entre os vídeos da biblioteca da UFSC: muitos mais visualizados em seu conjunto do que o os vídeos das outras bibliotecas.

Por último se pesquisou a duração dos vídeos: tanto o total dos canais das bibliotecas quanto a média de duração dos vídeos. A biblioteca da UFGM, através do programa de rádio apresenta 21 horas e 51 minutos no canal. Em segundo lugar a biblioteca da UFSC com 6 horas e 31 
minutos, UNB com 2 horas e 19 minutos, a biblioteca da FURG com 1 hora e 59 minutos, PUCRIO 43 minutos e as bibliotecas da UFPB, UFJF, 8 minutos cada uma, e UEL e UFU com 6 e 4 minutos, respectivamente. 0 tempo médio de duração dos vídeos oscila entre os 14 minutos da biblioteca da UFMG, quase 9 para UFSC, FURG (5 min.), UFU e UFPB (4 min.), UNB (3) e UEL, UFJF e PUCRIO com 2 minutos.

\section{Considerações finais}

Os 235 vídeos analisados nesta pesquisa têm uma duração total de 33 horas, 55 minutos e 58 segundos e somam 125.222 visualizações na plataforma. Isto demonstra que as bibliotecas universitárias podem produzir conteúdos visuais. Embora esta pesquisa não valore a qualidade técnica dos mesmos, é certo que alguns vídeos tenham alguns problemas de imagem ou som, em particular aqueles que são mais antigos. Há que tentar elevar o nível de qualidade oferecido, mas com a tecnologia que se dispõe na atualidade, este problema poderia ser solucionado sem dificuldades.

Nem todas as bibliotecas utilizam a plataforma da mesma forma. Às vezes é um simples armazém de conteúdo audiovisual. Em outros momentos é usado como um recurso que se utiliza isolado (um simples vídeo tutorial para um assunto) ou também pode ser empregado dentro da estratégia da biblioteca. Uma das chaves de ter um canal no YouTube não é simplesmente o fato de estar presente, é preciso um planejamento estratégico, conhecer as necessidades dos usuários, pensar quais são os objetivos da instituição e utilizar métricas para saber se está no caminho certo. Os vídeos são um complemento ideal dentro da estratégia de marketing de relacionamento mediados pelas mídias sociais.

Existem muitas possibilidades para utilizar YouTube na biblioteca: gravação de breves aulas expositivas de assuntos de interesse para os usuários; registro de eventos que aconteçam na biblioteca ou na universidade; explicações dos bibliotecários ou dos próprios usuários sobre como usar os serviços da biblioteca; apresentação de procedimentos da universidade: como conseguir a carteira de estudante, como criar um email institucional, etc.

Não se achou nenhuma biblioteca que utilizasse YouTube ao vivo (Live), pois esta é uma interessante possibilidade, por exemplo, para transmitir palestras. Se há uns anos ter um canal de TV era um luxo para uns poucos, hoje está mais perto de todos com a boa utilização das ferramentas que a internet deixa à disposição usar o audiovisual produzido nas mídias sociais. Em pesquisas futuras os estudos aprofundar-se-ão na perspectiva dos vídeos na plataforma social como estratégia de relacionamento procurando novos focos de inovação no âmbito das unidades de informação.

\section{Referências}


BRITO, J. L.; SILVA, P. M. Ferramentas da web 2.0 em bibliotecas universitárias: um estudo de caso. Biblionline, v. 6, n. 33, p. 23-33, 2011. Disponível em: <http://dci.ccsa.ufpb.br/enebd/index.php/enebd/article/view/132>. Acesso em: 30 ago. 2016.

DIB, S. F. et al. Innovative professional practices in Library Science. In: REUNIÓN SATÉLITE DE IFLA LAC, Ohio, 2016. Futuro de las Bibliotecas: ¿lo que va a ser el acervo y los servicios en 2030? Ohio, 2016, p. 1-16.

GIL, A. C. Como elaborar projetos de pesquisa. São Paulo: Atlas, 2002.

GIL, A. C. Como elaborar projetos de pesquisa. 5.ed. São Paulo: Atlas, 2010.

HOLMBERG, K. et al. What is Library 2.0? Journal of Documentation, $v$. 65, n. 4, p. 668-681, 2009. Disponível em: <http://doi.org/10.1108/00220410910970294>. Acesso em: 29 ago. 2016.

KANTER, B.; FINE, A. H. Mídias sociais transformadoras: ação e mudança no terceiro setor. São Paulo: Évora, 2011.

LEVACOV, M. Tornando a informação disponível: o acesso expandido e a reinvenção da biblioteca. In: MARCONDES, C. $\mathrm{H}$; KURAMOTO, $\mathrm{H}$.; TOUTAIN, L. B; SAYÃO, L. (Orgs.). Bibliotecas digitais: saberes e práticas. 2. ed. Salvador, BA: EDUFBA; Brasília: IBICT, 2006. p. 207-224.

MANESS, J. M. Library 2.0 theory: Web 2.0 and its Implications for Libraries. Webology, v. 3, n. 2, p. 1-10, 2006. Disponível em: <http://www.webology.org/2006/v3n2/a25.html>. Acesso em: 27 ago. 2016.

MARTEL, F. Smart: o que você não sabe sobre a internet. Rio de Janeiro: Civilização Brasileira, 2015.

ORGANIZAÇÃO DE COOPERAÇÃO E DESENVOLVIMENTO ECONÔMICO. Oslo manual: proposed guidelines for collecting and interpreting technological innovation data, 2005. Disponível em: < http://www.oecd.org/science/inno/2367580.pdf>. Acesso em: 13 ago. 2016

RIBEIRO, A. A. YouTube, a nova TV corporativa: o video na web como estratégia de comunicação pública e empresarial. Florianópolis: Combook, 2013.

RIBEIRO, A.; LEITE, R. S.; LOPES, H. E. G. Análise do uso das ferramentas de redes sociais em bibliotecas universitárias brasileiras. $R D B C I$, v. 12, n. 3, p. 5-27, 2014.

RICHARDSON, R. J. Pesquisa social: métodos e técnicas. São Paulo: Atlas, 1989.

SI, L.; SHI, R.; CHEN, B. An investigation and analysis of the application of Web 2.0 in Chinese university libraries. The Electronic Library, v. 29 n. 
5, p. 651-668, 2011. Disponível em: <https://doi.org/10.1108/02640471111177080>. Acesso em: 15 ago. 2016

TRIPATHI, M.; KUMAR, S. Use of Web 2.0 tools in academic libraries: a reconnaissance of the international landscape. International Information and Library Review, v. 42, n. 3, p. 195-207, 2010.

TOMÁEL, M. I. Categorias e dimensões do compartilhamento da informação. In: TOMÁEL, M. I. (Org.). Compartilhamento da informação. Londrina: Eduel, 2012. p. 6-20.

VIEIRA, D. V.; BAPTISTA, S. G.; CERVERÓ, A. C. Adoção da Web 2. 0 em bibliotecas de universidades públicas espanholas: perspectivas de interação do bibliotecário com as redes sociais. Perspectivas em Ciência da Informação, v. 18, n. 2, p. 167-181, 2013.

WEBOMETRICS. Methodology [2006?]. Disponível em: <http://www.webometrics.info/en/Methodology>. Acesso em: 19 ago. 2016

YOUTUBE. Estatísticas. [2016?]. Disponível em: <https://www.youtube.com/yt/press/pt-BR/statistics.html>. Acesso em: 30 ago. 2016 